\title{
SISTEMA DE AUTOMAÇÃO DE IRRIGAÇÃO DO PLANTIO
}

\author{
Camila Pires Cremasco Gabriel ${ }^{1}$ \\ Diego Luiz Cavalca ${ }^{2}$ \\ Luiz Fernandes da Silva Sales ${ }^{3}$
}

\begin{abstract}
RESUMO: O mundo está mudando e a água está ficando cada vez mais escassa. Uma das maiores fontes de desperdício é a agricultura, onde no Brasil, cerca de $72 \%$ da água potável é utilizada para esta finalidade. Desperdício de água faz mal para o ambiente e consequentemente faz mal para a plantação. A partir de revisões bibliográficas, este artigo visa oferecer uma visão abrangente sobre o desenvolvimento de um sistema que gerencie automaticamente a irrigação de qualquer tipo de plantio, com base em sensores que realizam diversos tipos de análises de solo e ambiente e também levando em questão parâmetros específicos como o tipo de cultivo em que o sistema estiver aplicado. Com base nos dados coletados pelos sensores e informados pelo produtor a respeito de sua plantação, este sistema, através de um algoritmo computacional, irá acionar automaticamente a irrigação do solo, aplicando com precisão a quantidade ideal de água que o plantio necessita naquele momento. Além da economia de água e seu grande impacto sócio-econômico, que é nosso maior foco em primeiro momento, esse sistema proporcionará cultivos mais prósperos, uma vez que a quantidade de água aplicada na irrigação do solo favorece o sucesso do plantio.
\end{abstract}

PALAVRAS-CHAVE: Água, Irrigação, Automação.

\section{SYSTEM PLANTING IRRIGATION AUTOMATION}

ABSTRACT: The world is changing and the water is becoming increasingly scarce. One of the major sources of waste is agriculture, where in Brazil, about $72 \%$ of the drinking water is used for this purpose. Waste water is bad for the environment and therefore is bad for planting. From literature reviews, this article aims to provide a comprehensive view on the development of a system that automatically manage the irrigation of any type of planting, based on sensors that perform various types of soil analysis and environment and also taking into question parameters specific such as type of cultivation in which the system is applied. Based on data collected by sensors and informed by the producer on his plantation, this system through a computational algorithm, will automatically trigger the irrigation of the soil by applying precisely the optimal amount of water that need planting now. In addition to the water savings and its great socio-economic impact, which is our main focus in the first instance, this system will provide more prosperous crops, since the amount of water applied to the soil irrigation favors the success of the planting.

KEYWORDS: Water, Irrigation, Automation.

\footnotetext{
${ }^{1}$ Doutora em Agronomia, UNESP.

camila@tupa.unesp.br

${ }^{2}$ Graduado em Téc. Em Análise e Desenvolvimento de Sistemas, UNILINS.

diegocavalca.ti@gmail.com

${ }^{3}$ Licenciado em Informática, UNILINS.

luiz_620@hotmail.com
} 


\section{Periódica Eletrânica

\section{PLANTACIÓN SISTEMA DE RIEGO DE AUTOMATIZACIÓN}

RESUMEN: El mundo está cambiando y el agua es cada vez más escasa. Una de las principales fuentes de residuos es la agricultura, donde en Brasil, cerca del $72 \%$ del agua potable se utiliza para este propósito. El agua residual es malo para el medio ambiente y por lo tanto, es malo para la siembra. A partir de revisiones de la literatura, este artículo pretende ofrecer una visión global sobre el desarrollo de un sistema que maneje automáticamente el riego de cualquier tipo de plantación, basado en sensores que realizan distintos tipos de análisis de suelos y el medio ambiente, y también teniendo en parámetros de interrogación específico como el tipo de cultivo en el que se aplica el sistema. Sobre la base de los datos recogidos por los sensores e informadas por el productor en su plantación, este sistema a través de un algoritmo computacional, se activará automáticamente el riego del suelo mediante la aplicación de forma precisa la cantidad óptima de agua que necesitan plantar ahora. Además de los ahorros de agua y su gran impacto socio-económico, que es nuestro principal objetivo, en primer lugar, este sistema proporcionará cultivos más prósperos, ya que la cantidad de agua aplicada al riego de suelos favorece el éxito de la plantación.

PALABRAS CLAVE: Agua, Riego, Automatización.

\section{INTRODUÇÃO}

É um paradoxo imaginar que um dos setores mais importantes para a economia de nosso país possa ser também um dos principais agentes de consumo e desperdício de água. A produção agrícola nacional consome $72 \%$ de toda água potável captada no Brasil, segundo dados da ANA (Agência Nacional de Águas).

Ainda não há dados oficiais sobre o desperdício de água na agricultura, mas algumas organizações não governamentais especulam que as perdas podem chegar $70 \%$.

"O último levantamento do Sistema Nacional de Informações sobre o Saneamento (Snis), do Ministério das Cidades, mostrou que a média de consumo diário de água de cada brasileiro é de 150 litros, o que resulta em um consumo médio anual de 10,4 trilhões de litros no país. Desse total, pouco mais de 7 trilhões são destinados à agricultura, que acaba desperdiçando cerca de 3 trilhões de litros de água." (Diego Antonelli).

É imprescindível deixarmos de falar sobre a questão do desperdício, uma vez que a maior parte de água é utilizada na área agrícola de forma irregular, levando assim, a termos problemas maiores em um futuro muito próximo com a questão hídrica. Estamos em uma grande expansão agrícola em nosso pais, seria uma excelente oportunidade de termos uma grande expansão em economia de água. A água é necessária para a produção dos nossos alimentos, mas também temos que ter a consciência de que essa mesma água um dia pode estar mais escassa em nosso meio, fazendo com que todos nós tenhamos grandes problemas 
para a nossa sobrevivência.

Para tanto existe a importância da conscientização sobre a utilização correta e eficaz deste bem que é muito precioso para que haja a existência da vida que cada vez mais está em evidência nos meios de comunicação, levando todos nós a uma reflexão constante sobre a escassez desta água que é necessária para a sobrevivência de todos os seres humanos e de plantas que estão envolvidas em nosso convívio social.

\section{DESPERDíCIO NO PROCESSO DE IRRIGAÇÃO}

A ineficiência no processo de irrigação é o principal responsável pelo desperdício hídrico no plantio, sendo vários os fatores que ocasionam esse malefício, onde o principal deles deseja o descaso do ser humano com a correta utilização da água que é de fácil acesso para todos nós.

Podemos classificar os diversos fatores que comprometem a irrigação em duas categorias: humanos e naturais.

Fatores naturais de desperdício podem ser considerados como, por exemplo, a evopotranspiração e ação do vento no plantio, que acabam gerando maior necessidade de água no solo.

Já os fatores humanos respondem de maneira majoritária pela deficiência da irrigação, uma vez que pela baixa instrução técnica e falta de artefatos necessários, acabam jogando água em excesso no plantio, que muitas das vezes acabam atrapalhando a produção dos alimentos. Uma vez que há imprecisão na irrigação, consequentemente alguns lugares da plantação podem receber mais água que outros.

Esses fatores, de maneira geral eleva de maneira exponencial o desperdício de água, aumentando os custos e diminuindo a produtividade da plantação. Consequentemente, observa-se que a falta de preparo por parte dos agricultores afeta a produção de seus produtos, levando os mesmos a terem prejuízos em sua produção ou até mesmo o elevado preço da produção para o consumidor final, pois o gasto desnecessário com água faz com que tenha outros gastos que ao final deverão ser computados para que o produtor consiga suprir suas necessidades. 


\title{
Periódica Eletranica

\begin{abstract}
"A ANA mostra que entre 2006 e 2010 houve um crescimento de $47,5 \%$ na demanda d'água para agricultura. Mais expandiram suas áreas irrigadas as bacias hodrográficas do Paraná (acréscimo de $88 \%$ ), do São Francisco $(73 \%)$, e do Araguaia-Tocantins (58\%). Essa expansão da agricultura irrigada, óbvio, utiliza mais água. Mas representa uma excelente notícia para o desenvolvimento sustentável do país." (Xico Graziano - O Estado de São Paulo).
\end{abstract}

É claro que não podemos deixar de mencionar que o Brasil é um país agrícola e se soubermos utilizar os recursos que temos em nossas mãos, continuaremos a ser um pais agrícola com grande desenvolvimento e que a cada dia que se passa a expansão é constante e com toda certeza devemos investir mais neste tipo de cultura, pois temos excelentes condições para que o país consiga avançar muito mais por esta questão. Mas, também temos que ter a consciência de que o uso racional da água é de fundamental importância para que tenhamos qualidade no que podemos oferecer para os seres humanos, levando assim a uma qualidade satisfatória de vida.

Se o produtor não tiver embasamento e orientação sobre a utilização da água, ele irriga como der, mas, se fazemos simulações de longo prazo, conseguimos saber quanto colocar de água em vez de jogar água à toa, levando assim, a uma economia satisfatória, ocasionado melhoras significativas na produção, obtendo produtos de melhor qualidade e apresentando preços atrativos na venda de destes itens para o consumidor final.

\section{SISTEMA DE SENSORES E ALGORITMO DE AUTOMAÇÃO}

Com o advento de novas tecnologias, novas possibilidades surgem na mesma velocidade, gerando soluções eficientes para grandes problemas, dentre eles um dos mais importantes que é a utilização da água de forma que não haja perdas, proporcionando a utilização necessária sem que haja prejuízos para os envolvidos na situação.

Esse artigo propõe o desenvolvimento de um sistema de automação de irrigação, no qual utiliza componentes eletrônicos para realizar a leitura de variáveis do plantio a fim de realizar um cálculo preciso de quanto e quando um solo deve ser irrigado. 


\section{Periódica Eletrânica

O projeto visa a melhoria na questão da irrigação das plantações existentes no nosso meio, levando a ter grande economia na utilização da água, reduzindo assim o impacto da crise hídrica que está em evidência nestes últimos meses.

Para realizar o processo computacional, utilizaremos um componente chamado Microcontrolador, no qual se resume em um aparato que permite processarmos algoritmos pré-definidos, similar a um computador convencional, mas de tamanho e custo muito reduzido, uma vez que o investimento financeiro para a questão tecnológica ainda é muito reduzido dentro da nossa realidade.

O microcontrolador consegue aumentar suas possibilidades através de módulos, nos quais agregam recursos poderosos, permitindo aplicar a automação de um processo mecânico em qualquer ambiente ou finalidade, isso inclui o nosso objetivo que é a área agrícola.

Alguns desses módulos funcionam como sensores, possibilitando a leitura precisa e diversificada dos fatores existentes no processo produtivo agrícola, como, por exemplo, a leitura de umidade do solo, temperatura do ar, incidência de chuva, etc.

Basicamente, o sistema irá coletar esses dados e, somado a especificação do tipo de cultura, realizar o cálculo constante da quantidade de água necessária para a irrigação necessária do solo durante todo o ciclo de vida do plantio, liberando água na medida e na hora certa, evitando desperdício e favorecendo a produtividade da colheita.

Este procedimento será satisfatório para o produtor, uma vez que o próprio sistema irá realizar todo o controle de irrigação, sempre mantendo a produção de acordo com o determinado para o bom desenvolvimento de seu plantio.

Com a implantação do sistema automatizado, o produtor perde a ideia de que ele está tendo um gasto a mais em sua produção e com isso percebe que a melhoria será constante para a sua área agrícola, deixando de perder tempo com a irrigação manual, o que o possibilitará expandir a sua área de plantio e ter rendimentos maiores com a sua produção.

De maneira geral, além de gerar uma economia considerável de água e energia, o sistema proposto neste artigo fornece novas perspectivas para o agronegócio, mitigando os riscos envolvidos no processo de irrigação do plantio.

Será possível enviar os dados coletados, juntamente com o histórico de 
irrigação, para um servidor, onde vários indicadores poderão ser gerados para que em um segundo momento, o produtor possa acompanhar seu negócio em temporeal de maneira abrangente, facilitando a tomadas de decisões com base em informações consistentes e precisas. Com base em relatórios emitidos e arquivos guardados em seu banco de dados, o produtor poderá fazer constantemente uma análise de sua produção e corrigir as falhas para que a cada ano ele consiga minimizar seus problemas e elevar sua produção, produzindo uma rentabilidade maior dentro da sua propriedade.

\section{RESULTADO}

Como resultado da solução proposta neste artigo, a diminuição do desperdício de água no processo de irrigação do plantio sofrerá impacto direto no cenário socioeconômico de toda a população, uma vez que grande parte da água potável disponível em nosso país é destinada ao setor agrícola. Com isso, a economia do setor agrícola será satisfatória, podendo ter reflexos positivos para o consumidor final.

\section{CONCLUSÃO}

Definitivamente, nosso país não sofre, essencialmente, de falta de água, mas sim de políticas de gestão de recursos hídricos, principalmente na agricultura.

Existe um mundo de possibilidades envolvidas na solução proposta neste artigo que, por ventura, poderão ser exploradas de acordo com sua evolução, mas o objetivo final é reduzir o uso da água potencializando a produtividade no plantio, gerando economia e sustentabilidade no setor agrícola. 


\section{Periádica Eletranica

\section{REFERÊNCIAS UTILIZADAS:}

FRANÇA, Júnia Lessa et al. Manual para normalização de publicações técnico-cientificas. 6 . ed. rev. e ampl. BeloHorizonte: UFMG, 2003. 230 p.

IBGE. Normas de apresentação tabular. 3. ed. 1993.

LAKATOS, Eva Maria; MARCONI, Marina de Andrade. Fundamentos de metodologia científica. 3. ed. rev. e ampl. São Paulo: Atlas, 1991. 270 p.

Agência Nacional das Águas. Balanço Hídrico no Brasil, Brasília, 05 de Jun. 2015. Disponível em: <http://balancohidrico.ana.gov.br/>. Acesso em: 05 jun. 2015.

Brasil Post. Com reajuste menor, Sabesp vai atrasar obras contra crise de água em SP, São Paulo, 05 de Jun. 2015. Disponível em: <http://www.brasilpost.com.br/news/agencia-nacional-deaguas/>. Acesso em: 05 jun. 2015.

Estadão. Irrigação agrícola e desperdício de água, São Paulo, 03 de Mar. 2015. Disponível em: <http://opiniao.estadao.com.br/noticias/geral,irrigacao-agricola-e-desperdicio-de-agua-imp-,1643238>. Acesso em: 05 de jun. 2015.

Brasil. A agricultura é vilã ou vítima na crise hídrica?, São Paulo, 04 de Mar. 2015. Disponível em: <http://www.bbc.co.uk/portuguese/noticias/2015/03/150302_agua_agricultura_pai>. Acesso em: 05 de jun. 2015.

ANTONELLI, D. Quase metade da água usada na agricultura é desperdiçada, São Paulo, 21 de Mar. 2015. Disponível em: <http://www.gazetadopovo.com.br/vida-e-cidadania/quase-metade-daagua-usada-na-agricultura-e-desperdicada-8cloqojyzd90xgtv7tdik6pn2>. Acesso em: 05 de jun. 2015.

RIBEIRO, M. Para não faltar água, multa por consumo excessivo deve ser permanente, São Paulo, 20 de Jan. 2015. Disponível em: <https://www.sosma.org.br/artigo/para-nao-faltar-agua-multapor-consumo-excessivo-deve-ser-permanente/>. Acesso em: 05 de jun. 2015.

Akatu. Setor industrial e agropecuário são campeões no consumo de água, São Paulo, 23 de Nov. 2006. Disponível em: <http://www.akatu.org.br/Temas/Cadeias-Produtivas/Posts/Setoresindustrial-e-agropecuario-sao-campeoes-no-consumo-de-agua>. Acesso em 05 de jun. 2015. 